\title{
Computer Chat Versus Mobile Chat: Effects of Different Chat Tools on EFL Speaking and Writing
}

\author{
Kim, Na-Young \\ (Sehan University)
}

\begin{abstract}
Kim, Na-Young. (2018). Computer chat versus mobile chat: Effects of different chat tools on EFL speaking and writing. STEM Journal, 19(2), 145-167.

This study explores the effects of different chat tools on EFL speaking and writing. A total of 41 Korean college students participated in this study. They were randomly divided into two groups: Computer chat $(n=20)$ and mobile chat $(n=21)$. During the 10 -week experiment, participants in computer chat engaged in chat through a computer, while those in mobile chat joined through a mobile phone. They participated in chat for 10 minutes twice a week. Speaking and writing pre-tests were administered before the treatment, while post-tests were administered after the treatment. Interviews were then conducted. Participants' oral and written performance was evaluated by examining fluency, accuracy, and complexity. For analysis, descriptive statistics, paired samples $t$-tests, independent samples $t$-tests, and a one-way ANCOVA were computed. Findings revealed that computer chat improved speaking fluency and complexity, while mobile chat developed speaking fluency as well as writing fluency and complexity. In particular, computer chat outperformed mobile chat in terms of speaking fluency and complexity. As for writing fluency and complexity, both computer and mobile chat turned out to be equally effective. Interview results indicated that all participants perceived online chat activities positively. Based on these findings, pedagogical implications and suggestions for future research have been drawn.
\end{abstract}

\section{INTRODUCTION}

The popular acceptance of the Internet has advanced the development of computermediated communication (CMC). CMC includes two different formats - asynchronous and synchronous. Asynchronous CMC neither requires the simultaneous interaction nor occurs in real time. However, synchronous $\mathrm{CMC}$ not only requires simultaneous interaction, but also occurs in real time. While asynchronous CMC technology includes emails, blogs and discussion forums, synchronous CMC encompasses various types of 
chat and conference.

Synchronous chat has been regarded as more beneficial than asynchronous chat. Compared to asynchronous interaction, synchronous chat requires less time but provides more social interaction. According to Warschauer (1996), synchronous CMC contributes to students' language fluency encouraging them to use more complex language both syntactically and lexically. The discourse of synchronous chat is more formal and complex than face-to-face interaction. Yoon and Han (2004) also proved that synchronous chat is beneficial for improving students' accuracy in language use. Regarding affective aspects, students have positively evaluated that the online chat is needed for their language learning. Kim (2017) claimed that students enjoy synchronous chat. In fact, synchronous chat is highly valued by students with its easiness and practicality to use, according to Choi (2004).

A synchronous $\mathrm{CMC}$ including chat also provides a rich context for exploratory talk by motivating language learners (Pilkington \& Walker, 2003). When used in a foreign language classroom, such tools can lead to target language development (Pennington, 1996). In addition, unlike in a face-to-face environment, ethnicity is not a factor in limiting participation in chat activities (Warschauer, 1996). Since communication through chat does not restrict participation, learners can participate more equally in language learning activities (Sullivan \& Pratt, 1996). Additionally, this synchronous interaction improves learners' confidence, decreasing dependence on the teacher (Kern, 1995). Consequently, it provides learner-centered learning environments and increases learner autonomy by providing a broad range of learning opportunities. It is said that new ways of language learning have been enabled with CMC technology.

Most CMC programs are considered to be useful for developing literacy skills, especially writing skills. Accordingly, many previous studies have underscored CMC software which can also facilitate the acquisition of communicative skills like listening skills and speaking skills (Kim, 2002). Despite a plethora of previous CMC studies, however, there are still gaps to be filled. Jeong (2010) noted that previous research on CMC has been mainly focused on asynchronous CMC, not synchronous CMC. Furthermore, only a few studies have examined the use of synchronous CMC, namely chat, in terms of both the speaking and writing development (Abrams, 2003; Chun, 1994; Warschauer, 1996). Since chat has blurred the traditional distinction between speaking and writing (Hyland, 2002), learners who show language competence in chat can transfer their competence to both speaking and writing (Chun, 1994). Given this, more research on chat in relation to speaking and writing needs to be explored. This study, therefore, addresses the question of whether synchronous CMC, chat, can enhance EFL learners' speaking and writing skills.

Technology which holds the capacity for language learning range from desktop 
computers to mobile phones and mobile devices are now social staple and nomadic, wireless, and handheld. Even though these portable devices have been regarded as beneficial for language learning and utilized in a language classroom (Chinnery, 2006), there has been little research on the effectiveness of mobile chat (Kim, 2017). Moreover, there has been a long-standing debate on whether language learning through a mobile phone has any significant effects (Chinnery, 2006; Kukulska-Hulme \& Shield, 2008; Pettit $\&$ Kukulska-Hulme, 2007). In light of this, more research studies on mobile chat tools also need to be conducted. Accordingly, this study seeks to explore the effects of different synchronous CMC tools, namely computer chat and mobile chat, on EFL speaking and writing skills. Three research questions were addressed as follows:

1. Are there any changes in EFL learners' speaking and writing performance as a result of the use of two different chat tools?

2. Are there any group differences in EFL learners' speaking and writing performance between the two different chat tools?

3. What are EFL learners' attitudes toward the two different chat tools?

\section{LITERATURE REVIEW}

\section{Computer Assisted Language Learning}

Computers have various pedagogical characteristics and they have been utilized in teaching and learning languages around the world. Most educators and professionals admit that computers affect the way teachers teach and learners learn a language (Kim, 2017) and this led to the prominence of computer assisted language learning (CALL). Particularly, the utilization of computers in the basic stage has been regarded as the most beneficial for students (Hani, 2014).

Computer use in a language classroom has proven advantageous in some respects. The utilization of computers has been found to facilitate language learning as well as develop learners' ability to analyze information, think critically, solve problems, and eventually, study independently (Smith, 2008). Al Abdel Halim (2009) reported significant increases in language learners' reading speed and comprehension through computer-assisted reading instruction. Furthermore, computers can be excellent supplementary materials to promote classroom instruction. They can not only enhance visual, verbal, and kinesthetic learning, but also provide hands-on learning with immediate feedback and collaborative instruction (Becker, 2000).

Hani (2014) insisted that CALL is an adequate medium for enhancing the quality of 
teaching and learning the language for the following reasons: 1) Computers are suitable for provoking fruitful classroom activities and they can help in the acquisition of four language skills (i.e. reading, writing, listening, and speaking), 2) they are also a useful tool for the integration of these four language skills, 3) computer technology helps learners to study a language both inside and outside the classroom, 4) it also provides authentic, individualized, and continuous teaching and learning activities, and 5) CALL reduces learners' apathy and a lack of the involvement in the learning process.

$\mathrm{Fu}$ (2013) also reported on the use of information and communication technology (ICT) in language education. Fu investigated the advantages of ICT integration in classroom settings, barriers and challenges encountered in the usage of ICT, factors influencing successful ICT integration, and teachers' attitudes toward and perceptions of utilizing ICT. Consequently, it led to more participation. ICT enabled learners to be more involved in the learning process. As a result, computers and computer associated technologies helped shift from teacher-centered approach to learner-centered approach (Lu, Hou, \& Huang, 2010).

AbuSeileek and AbuSa'aleek (2012) argued that CALL has entered a new era with the emergence of the Internet. According to them, computers have enormous potential as teaching aids. By providing different learning tasks, they can assist both teachers and learners. Han (2008) also emphasized the remarkable development of computers and the Internet and suggested that more and more language practitioners should utilize computers for foreign language learning and teaching. With an advancement of the Internet, the computer assisted learning technology is deemed an ideal tool for foreign language learning and teaching. It supports a functional, learner-centered approach to knowledge. According to Riasati, Allahyar, and Tan (2012), technology, in particular, should be employed in language instruction to enhance teaching and learning.

English became a significant instrument for international communication with the advent of the Internet and its associated technologies. Although the use of computers in language learning and teaching brings a positive effect to the achievement of learners, some barriers to their wide implementation are still observed (Hani, 2014). Against technology-driven pedagogy, Salaberry (2001) advocated that it is not clear that modern technologies have offered the same pedagogical advantages as traditional language instruction. In addition, teachers cannot be fully replaced or neglected by the computer. A lack of authentic, efficient, and effective programs is frequently cited by language teachers owing to their reluctance to incorporate technology assisted learning tools in their own classroom practice (Hani, 2014). Utilizing technology for language learning requires establishing effective instructional programs. Han (2008) also put importance on adequate task design for chat. According to Colpaert (2004), it is important to develop the language learning environment prior to deciding on the role of technology, focusing on learners ahead of the technology. Beatty (2003) suggested that language teachers should be careful 
when investing time and money in unproven technologies.

\section{Mobile Assisted Language Learning}

"A computer is better than a mobile phone for handling various types of information such as visual, sound, and textual information, but mobile phone is superior to a computer in portability. And some students don't have their own computer" (Yamaguchi, 2005, p. 57). Considering the history of CALL, a period of professional development was followed by a period of amateur development by teachers and researchers. Accordingly, according to Colpaert (2004), language teachers and researchers can also develop their own mobile assisted language learning (MALL) applications. It seems quickly headed for a world in which MALL is a fashionable channel for foreign language acquisition.

As a sub-branch of CALL, MALL has become a popular topic of interest in teaching and learning a foreign language. So far, studies have investigated the effects of MALL on developing different aspects and skills of a language. Studies (Lu, 2008; Saran, Seferoglu, \& Cagiltay, 2009; Thornton \& Houser, 2005) have indicated that mobile phones are put into practice for educational purposes more frequently than the other MALL devices. When it is considered that mobile phones are cheaper, lighter, and more accessible as well as practical compared to many other mobile devices (ITU, 2009) and mobile assisted language learning can be self-paced as a learner is in control, managing the pace of learning (Chinnery, 2006), it is easy to understand the reasons behind the popularity of mobile phones in research and practice.

The first attempts in language teaching were discussed by Brown (2001). His study revealed that MALL was perceived in the same way as CALL. There were vocabulary lessons, quizzes, and translations. As a result of exploring mobile phone use in language learning, mobile phones turned out to be helpful in improving language learning. Kiernan and Aizawa (2004) conducted a study on the use of mobile phones and its effects on language learning. They drew attention to their potential advantages in language learning and combined a MALL approach with task-based learning. Nah, White, and Sussex (2008) looked into the potential use of mobile phones to develop EFL listening skills. They carried out a study using mobile phones to access the Internet for learning purposes. At the end of their quasi-experimental study, participants were more motivated to learn a language through mobile phones online and revealed positive attitudes toward using mobile phones as a means of learning. Saran, Seferoglu, and Cagiltay (2009) studied the opportunities to improve English pronunciation by using MALL. Some studies have dealt with MALL as a substitute for traditional learning materials and used as a distance learning tool. The correlation between learning motivation and MALL to improve EFL proficiency has also been studied (Nah, White, \& Sussex, 2008). 
Most MALL studies have examined learning opportunities for vocabulary acquisition through SMS and MMS functions on the mobile phone and they have shown that mobile phones were effective vocabulary learning devices (Saran, Seferoglu, \& Cagiltay, 2009). Thornton and Houser (2005) revealed that learners who received mobile phone assisted vocabulary lessons developed more vocabulary words than those who studied the same set of vocabulary in class. Following the same path, $\mathrm{Lu}$ (2008) asserted that mobile phones are more effective learning tools than the traditional pen-and-paper based in vocabulary learning. In particular, $\mathrm{Lu}$ emphasized the importance of participation in vocabulary learning activity because the participants engaged in the activity with a high frequency learned more vocabulary than those with a less frequency.

However, despite the widespread use of mobile phones and their sophisticated functions, MALL has challenges and limitations (Chinnery, 2006). Most studies on MALL have been carried out to see its effectiveness on teaching and learning vocabulary in general (Lu, 2008; Thornton \& Houser, 2005). It has also been claimed that mobile phones cannot justify their expense and the same learning outcomes can also be attained with books, desktop computers, or even TV programs (Fallahkhair, Pemberton, \& Griffiths, 2007). Kukulska-Hulme and Shield (2008) revealed a different criticism directed at MALL, emphasizing the absence of a full exploitation of its mobility and portability. That is, it casts doubts on the sufficiency of evidence to prove its efficacy in language learning. Furthermore, according to Pettit and Kukulska-Hulme (2007), users rarely perceive their potential as a language learning tool and only a minority of them use mobile phones for learning purposes.

In spite of the existence of research on some aspects of MALL in language learning and teaching, the literature still lacks sufficient studies investigating its effects. Furthermore, it seems the debate on MALL will continue. Thus, research is needed to contribute to the literature as well as the educational practice by eliciting evidence for the practical use and effectiveness of MALL in EFL class.

\section{METHODOLOGY}

\section{Participants}

A total of 41 college students in Korea participated in this study. They were taking an English class as a general education requirement and their fields of study varied from Humanities to Physics. They were attending the class to improve their general English skills including speaking and writing skills. The participants' age ranged from 20 to 23 .

To examine the effectiveness of the use of different chat tools, this study employed the 
experimental design with two chat groups: Computer chat group and mobile chat group. All of the participants were assigned to one of the following conditions: Computer chat $(n=20)$ and mobile chat $(n=21)$. For the homogeneity test, speaking and writing pre-test scores of the computer chat group were compared with those of the mobile chat group. The test results were also used to assess the participants' English proficiency. Their scores ranged from 20.00 to 22.50 out of 45 , interpreted as low proficiency levels. $<$ Table $1>$ shows the descriptive data and the results of the homogeneity test.

TABLE 1

Results of the Homogeneity Test

\begin{tabular}{|c|c|c|c|c|c|c|c|}
\hline & & \multicolumn{2}{|c|}{ Computer Chat $(n=20)$} & \multicolumn{2}{|c|}{ Mobile Chat $(n=21)$} & \multirow{2}{*}{$t$} & \multirow{2}{*}{$p$} \\
\hline & & $M$ & $S D$ & $M$ & $S D$ & & \\
\hline \multirow[t]{3}{*}{ Speaking test } & Fluency & 8.75 & 3.65 & 8.78 & 2.42 & .040 & .968 \\
\hline & Accuracy & 0.41 & 0.37 & 0.39 & 0.29 & .234 & .816 \\
\hline & Complexity & 1.28 & 0.57 & 1.19 & 0.20 & .641 & .525 \\
\hline \multirow[t]{3}{*}{ Writing test } & Fluency & 10.14 & 2.45 & 8.46 & 1.95 & 2.427 & .020 \\
\hline & Accuracy & 0.63 & 0.23 & 0.60 & 0.27 & .483 & .632 \\
\hline & Complexity & 1.63 & 0.35 & 1.39 & 0.44 & 1.885 & .067 \\
\hline
\end{tabular}

No significant differences were found among the speaking pre-test scores of the computer chat group and the mobile chat group for all aspects: Fluency $(t=.040, p>.05)$, accuracy $(t=.234, p>.05)$, and complexity $(t=.641, p>.05)$. That is, both groups had the equal proficiency of English speaking in terms of fluency, accuracy, and complexity.

As for the writing pre-test, there were no significant differences observed between the computer chat group and the mobile chat group for two aspects: Accuracy $(t=.483, \mathrm{p}$ $>.05)$ and complexity $(t=1.885, p>.05)$. This result indicates that participants' writing skills in terms of accuracy and complexity were approximately same before the experiment began. For fluency, however, a statistical significance was shown $(t=2.427$, $p=.020)$, indicating that the two groups were not homogeneous for writing fluency before treatment.

\section{Procedures}

The current study explores the effects of different chat tools, namely computer chat and mobile chat, on EFL speaking and writing skills. For the present study, pre-posttest design was employed to obtain pre-test measures of the outcome prior to administering the treatment, followed by post-tests on the same measures after the treatment occurred.

Data were collected in a regular English session. Firstly, participants took a speaking 
and writing pre-test. For the test, they were asked to complete oral and written narrative tasks regarding their memorable events. These storytelling tasks were chosen because it is a useful medium for eliciting learners' personal experiences and ideas (Skehan, 2001). A narrative task requires learners to produce a story within a framework set up by the task. This type of task is popular in language research and testing as it provides language learners with extended opportunities to tell their personal stories in the outside world (Kiernan, 2005).

The narrative tasks employed in this study were time-constrained tasks. Following the previous study (Yuan \& Ellis, 2003), time constraints were imposed. For both oral and written narrative tasks, participants were given 10 minutes for planning. During task performance, 8 minutes were allowed for their oral performance and 15 minutes for the written performance. All participants' performance was recorded for transcription and analysis. Two raters evaluated their oral and written output (see Data Analysis for details).

FIGURE 1

Computer Chat and Mobile Chat

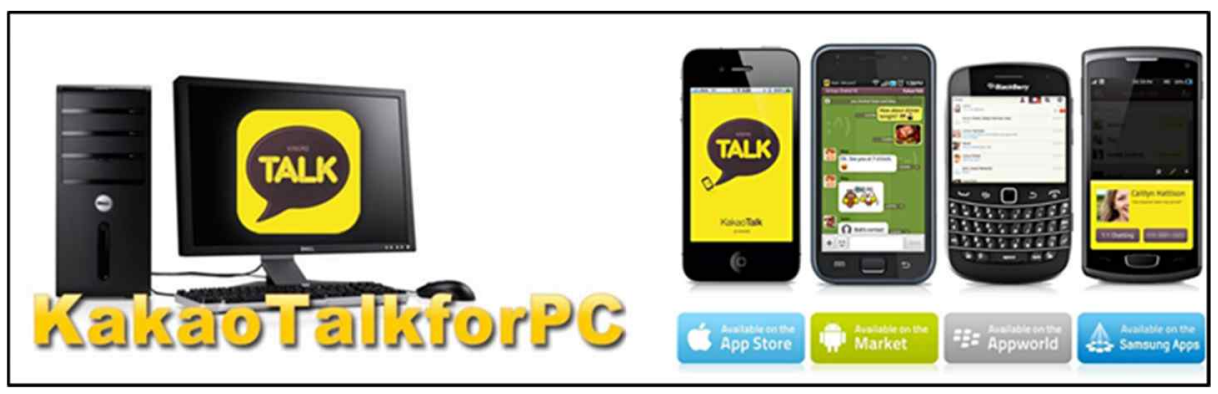

During the experiment, participants in computer chat group engaged in chat through a computer while those in mobile chat group joined the chat through a mobile phone. KakaoTalk application was employed for the present study. As a free messaging app, this is part of popular culture in Korea with the ease of implementation (Pollard, 2015). This chat application is available on the mobile phone. And also, it can be downloaded and installed on the computer. KakaoTalk was chosen because it has helped EFL learners facilitate communication (Han \& Kim, 2016). See $<$ Figure 1 $>$ above.

There were 20 chat sessions in total for 10-week experimental period. All participants joined in chat for 10 minutes twice a week. Chat topics were varied from family relations to school life. The participants were able to choose topics from those listed in The Internet TESL Journal (http://iteslj.org/questions/). The teacher's role was just a facilitator to encourage both two groups to engage in chat. In order to see whether the different types of chat tools are responsible for a result, all other variables in each group remain the same. 
After all chat sessions ended, there was a speaking and writing post-test with the same tasks as for the pre-test.

Following the speaking and writing post-test, there was a focus group interview in order to explore the participants' reactions to chat. For the interview, participants were informed to sincerely respond to the question according to their own English learning experience. It was a 30-minute semi-structured interview. Five interviewees from each group were asked the same interview questions prepared in advance. Other questions were also introduced during the interview, as needed. With the semi-structured interview, it was possible to elicit comprehensive information from the participants (Dörnyei, 2007).

\section{Data Analysis}

A total of 164 oral and written narrative performance was collected. They were measured by two EFL teachers certified in TESOL. They were bilingual in English and Korean. They have been teaching English speaking and writing in EFL fields for more than 6 years. A short training session was held prior to the actual rating process began to ascertain the clarity of rubric. In case of differences revealed between the two raters, the final score was the mean score given by them. Inter-rater reliability was more than .90 .

All of the participants' oral and written production were evaluated by examining fluency, accuracy, and complexity. EFL research has generally employed these three measures to assess the learners' performance (Larsen-Freeman, 2006). In order to undertake this analysis, participants' oral performance was coded for words, clauses, AS-units, and errorfree AS-units. Foster, Tonkyn, and Wigglesworth (2000) suggested that this method can best capture the features of oral performance and most appropriately account for utterances used for communication. Participants' written performance was also coded for words, clauses, T-units, and error-free T-units. Wolfe-Quintero, Inagaki, and Kim (1998) claimed that T-unit based measures are well-established measures of foreign language writing.

In terms of oral performance, fluency was measured through the number of words per AS-unit, which is a good measure for fluency (Ahmadi \& Sadeghi, 2016). Accuracy was measured through the number of error-free AS-units per AS-unit. About complexity, it was measured through the number of clauses per AS-unit. When it comes to written performance, fluency was measured through the number of words per T-unit. Writing accuracy was measured through the number of error-free T-units per T-unit. Complexity was measured through the number of clauses per T-unit. $<$ Table $2>$ shows a description of these three measures, adopted from the previous studies (Foster, Tonkyn, \& Wigglesworth, 2000; Larsen-Freeman, 2006; Wolfe-Quintero, Inagaki, \& Kim, 1998), 
TABLE 2

Measures of Fluency, Accuracy, and Complexity

\begin{tabular}{llll}
\hline \hline Measures & & & \\
\hline Oral Products & Fluency & W/AS & the ratio of words to AS-units \\
& Accuracy & EFAS/AS & the ratio of error-free AS-units to AS-units \\
& Complexity & C/AS & the ratio of clauses to AS-units \\
Written Products & Fluency & W/T & the ratio of words to T-units \\
& Accuracy & EFT/T & the ratio of error-free T-units to T-units \\
& Complexity & C/T & the ratio of clauses to T-units \\
\hline
\end{tabular}

Scores of fluency, accuracy, and complexity obtained by analyzing the compositions were fed into SPSS Version 21 program for further analysis. Descriptive statistics were computed for the all analyses. As the statistical means of analysis, paired samples $t$-tests were administered to compare the scores between pre- and post-tests. Independent samples $t$-tests were utilized to measure differences between the two groups. For the present research, a one-way analysis of covariance (ANCOVA) was also employed to determine effects of different chat tools. When a significant difference was found, a pre-test score was used as a covariate. Interview results to explore the participants' reactions to chat were analyzed using content analysis method.

\section{RESULTS AND DISCUSSION}

\section{Changes in EFL Speaking and Writing Skills}

This study explored the effects of different chat tools, computer chat and mobile chat, on EFL speaking and writing. Paired samples $t$-tests were conducted to see whether there were any significant changes between pre- and post-tests. $<$ Table $3>$ below represents descriptive statistics as well as $t$-test results. Statistically significant differences were observed in two groups.

In terms of speaking pre- and post-tests for computer chat group, both fluency and complexity reached statistical significance. In other words, there were significant changes in speaking skills regarding fluency $(t=3.487, p=.002)$ and complexity $(t=3.873, p$ $=.001)$. 
TABLE 3

Paired Samples $T$-Test Results

\begin{tabular}{|c|c|c|c|c|c|c|c|}
\hline & & \multicolumn{2}{|c|}{ Pre-Test $(n=41)$} & \multicolumn{2}{|c|}{ Post-Test $(n=41)$} & \multirow{2}{*}{$t$} & \multirow{2}{*}{$p$} \\
\hline & & $M$ & $S D$ & $M$ & $S D$ & & \\
\hline \multicolumn{8}{|l|}{ Computer Chat } \\
\hline \multirow[t]{3}{*}{ Speaking Test } & Fluency & 8.75 & 3.65 & 12.69 & 4.39 & 3.487 & .002 \\
\hline & Accuracy & 0.41 & 0.37 & 0.33 & 0.33 & 1.013 & .324 \\
\hline & Complexity & 1.28 & 0.57 & 1.77 & 0.62 & 3.873 & .001 \\
\hline \multirow[t]{3}{*}{ Writing Test } & Fluency & 10.14 & 2.45 & 10.19 & 3.41 & .065 & .949 \\
\hline & Accuracy & 0.63 & 0.23 & 0.70 & 0.31 & .924 & .367 \\
\hline & Complexity & 1.63 & 0.35 & 1.78 & 0.51 & 1.015 & .323 \\
\hline \multicolumn{8}{|l|}{ Mobile Chat } \\
\hline \multirow[t]{3}{*}{ Speaking Test } & Fluency & 8.78 & 2.42 & 9.66 & 2.10 & 2.389 & .027 \\
\hline & Accuracy & 0.39 & 0.29 & 0.45 & 0.32 & .936 & .360 \\
\hline & Complexity & 1.19 & 0.20 & 1.35 & 0.36 & 1.685 & .108 \\
\hline \multirow[t]{3}{*}{ Writing Test } & Fluency & 8.46 & 1.95 & 10.35 & 2.27 & 7.678 & .000 \\
\hline & Accuracy & 0.60 & 0.27 & 0.51 & 0.33 & 1.173 & .255 \\
\hline & Complexity & 1.39 & 0.44 & 1.77 & 0.45 & 3.967 & .001 \\
\hline
\end{tabular}

To be specific, as for fluency, the mean score on the speaking pre-test was 8.75 while 12.69 on the speaking post-test. About complexity, the mean score on the pre-test was 1.28 whereas 1.77 on the post-test. These findings indicate that participants who engaged in computer chat improved their speaking fluency. The participants also increased their speaking complexity as a result of engaging in computer chat. As the learner's language skills advance, his/her language becomes more sophisticated. From the findings of this study, it can be inferred that computer chat is beneficial for developing speaking complexity.

In the case of mobile chat group, statistically significant changes were also observed in both speaking and writing tests. As regards speaking pre- and post-tests, fluency reached statistical significance $(t=2.389, p=.027)$. As for writing pre- and post-tests, there were significant differences witnessed regarding fluency $(t=7.678, p=.000)$ and complexity $(t=3.967, p=.001)$. Specifically, participants in mobile chat group improved their speaking fluency after engaging in mobile chat, with the mean scores of 8.78 on the speaking pre-test and 9.66 on the speaking post-test. This means that the participants' ASunit length, words per AS-unit, increased with time. They also developed their writing fluency from the mean score of 8.46 on the writing pre-test to that of 10.35 on the writing post-test. This indicates that participants' written performance became more fluent after experiencing mobile chat. In terms of complexity, the mean scores also jumped from 1.39 on the pre-test to the 1.77 on the post-test. 
Results of the present study support previous research which suggests online chat activities improve speaking performance. According to Han and Kim (2016), advanced technologies designed to enable learners to develop speaking skills are prevalent now. Particularly, this study shows that both computer chat and mobile chat can improve EFL speaking fluency. This supports the previous study (Abrams, 2003), reporting that synchronous chat enabled learners to produce more language output. As Hudson and Bruckman (2002) pointed out, online chat can be a marker of increasing fluency. In addition, computer chat turned out to develop EFL learners' speaking complexity. Considering that complexity is related to a learner's language proficiency (Ellis, 2009), computer chat can lead to complexity improvement as well as overall proficiency development. Furthermore, mobile chat can also enhance learners' writing fluency. As well as writing complexity. Wolfe-Quintero, Inagaki, and Kim (1998) insisted that the more complex the composition is, the more clauses there are per T-unit. According to Warschauer (1996), online chat contributes to writing fluency encouraging the learners to use more complex language syntactically. Findings of the present study suggest that mobile chat can be beneficial for improving both EFL writing fluency with writing complexity.

As far as accuracy is concerned, there was no significant differential effect between the groups for both speaking and writing tests. Interestingly, participants in both two groups benefited from chat activities on fluency and complexity, but they failed to attain the high level to produce accurate language. Previous research (Volle, 2005) also reported a decrease in accuracy to as an outcome of participating in online chat. Yuan and Ellis (2003) suggested the trade-off effects, indicating that participants' limited attentional resources in fluency and complexity were gained at the loss of accuracy. According to Kern (1995), the participants' reduced attention to accuracy might be caused by the nature of rapid pace of chat. Since turn-taking is fast in chat, accuracy is at stake. Wolfe-Quintero, Inagaki, and Kim (1998) also claimed that the more words are produced, the more errors are shown.

As a matter of fact, there have been arguments over the role of chat in increasing accuracy either in speaking or writing (Jeong, 2010). According to Kern (1995), there is a possibility of learners' diminished attention to accuracy, caused by the fast pace of chat modes. Findings from the current study also support this. However, this is contradictory to the assumption that chat can be beneficial for learners due to increasing learners' awareness of the language forms (Warschauer, 1996). Considering this, the question as to whether chat can help increase accuracy in speaking and writing has required more empirical studies. 


\section{Group Differences in EFL Speaking and Writing}

In order to examine the use of different chat tools, the experimental design employed two chat groups: Computer chat group and mobile chat group. There was a homogeneity test before treatment to establish that they were homogenous. As stated in $<$ Table $1>$ in the previous section, there were no significant differences among the speaking pre-test scores between the two groups. In terms of the writing pre-test, however, a significant difference was observed between groups for fluency.

Therefore, to determine whether there were any significant group differences in speaking and writing skills as a result of participating in online chat, independent samples $t$-tests were carried out for the speaking and writing post-tests. As for writing fluency, since the two groups were not homogeneous before treatment, an ANCOVA was employed to analyze fluency on the writing post-test. $<$ Table $4>$ indicates independent $t$-test results, while $<$ Table $5>$ shows ANCOVA results for writing fluency.

TABLE 4

Independent $\boldsymbol{T}$-Test Results of the Speaking and Writing Post-Test

\begin{tabular}{|c|c|c|c|c|c|c|c|}
\hline & & \multicolumn{2}{|c|}{ Computer Chat $(n=20)$} & \multicolumn{2}{|c|}{ Mobile Chat $(n=21)$} & \multirow{2}{*}{$t$} & \multirow{2}{*}{$p$} \\
\hline & & $M$ & $S D$ & $M$ & $S D$ & & \\
\hline \multirow[t]{3}{*}{ Speaking Test } & Fluency & 12.69 & 4.39 & 9.66 & 2.10 & 2.795 & .009 \\
\hline & Accuracy & 0.33 & 0.33 & 0.45 & 0.32 & 1.187 & .243 \\
\hline & Complexity & 1.77 & 0.62 & 1.35 & 0.36 & 2.638 & .013 \\
\hline \multirow[t]{2}{*}{ Writing Test } & Accuracy & 0.70 & 0.31 & 0.51 & 0.33 & 1.918 & .062 \\
\hline & Complexity & 1.78 & 0.51 & 1.77 & 0.45 & .062 & .951 \\
\hline
\end{tabular}

TABLE 5

ANCOVA Results of the Writing Post-Test

\begin{tabular}{|c|c|c|c|c|c|c|c|}
\hline & & \multicolumn{2}{|c|}{ Computer Chat $(n=20)$} & \multicolumn{2}{|c|}{ Mobile Chat $(n=21)$} & \multirow{2}{*}{$F$} & \multirow{2}{*}{$p$} \\
\hline & & $M$ & $S D$ & $M$ & $S D$ & & \\
\hline Writing Test & Fluency & 10.19 & 3.41 & 10.35 & 2.27 & 3.246 & .080 \\
\hline
\end{tabular}

As can be seen from $<$ Table $4>$ and $<$ Table $5>$, there were significant differences between the two groups in terms of speaking fluency $(t=2.795, p=.009)$ and speaking complexity $(t=2.638, p=.013)$. To be more specific, speaking fluency of the computer chat group after treatment $(M=12.69)$ was higher than those of the mobile chat group (M =9.66). Speaking fluency of the computer chat group $(M=1.77)$ was also higher than those of the mobile chat group (1.35).

Findings of the present study reveal that computer chat is more beneficial than mobile 
chat for improving speaking fluency and complexity. In terms of other aspects, no group differences were witnessed. That is, computer chat and mobile chat are equally effective because the group differences were not significant to $95 \%$ confidence interval. In particular, given that post-test scores were higher than pre-test scores except accuracy, as stated in $\langle$ Table 3$\rangle$, the two chat tools can be considered as equally beneficial for developing writing fluency and complexity. To sum up, computer chat allows learners to produce more oral output and make their spoken language more sophisticated, compared to mobile chat. However, both computer chat and mobile chat can lead to more written output with syntactically more complicated language.

In the current study, the potential of MALL was compared with CALL. Yamaguchi (2005) stated that "A computer is better than a mobile phone for handling various types of information such as visual, sound, and textual information, but mobile phone is superior to a computer in portability. And some students don't have their own computer" (p. 57). Previous research has reported that computers have various pedagogical features. According to Smith (2008), the utilization of computers has been found to facilitate language learning. Hani (2014) insisted that CALL is an adequate medium for enhancing the quality of language learning because computers can help in the acquisition of four language skills including speaking skills. According to Hani, a number of studies have regarded computers as the most beneficial tool for learners. This study provides evidence that chat through computers play a more positive role in enhancing EFL speaking fluency and complexity.

The current study also proved that both computer chat and mobile chat played a positive part in increasing writing fluency and writing complexity. Even though previous studies have investigated the effects of MALL on developing language skills (Kiernan \& Aizawa, 2004; Nah, White, \& Sussex, 2008; Thornton \& Houser, 2005), most of them have been carried out to see its effectiveness on vocabulary learning and teaching in general. In addition, according to Fallahkhair, Pemberton, and Griffiths (2007), mobile phones cannot justify their expense because the same learning outcomes can also be attained with books, desktop computers, or even TV programs at a substantially lower cost. Kukulska-Hulme and Shield (2008) also pointed out the absence of a full exploitation of their mobility and portability. Furthermore, the MALL literature still lacks sufficient studies investigating its pedagogical effects. There are doubts on the sufficiency of evidence to prove its efficacy in language learning. Considering this, this study sheds light on the effectiveness of mobile phones on EFL writing skills. The learning effects related to writing fluency and complexity can be as valid for MALL as it can be for CALL. This derives implications as to whether MALL could be utilized for EFL learning and teaching. 


\section{Reactions Toward Computer Chat and Mobile Chat}

In an effort to explore participants' reactions to two chat tools, focus-group interviews were performed. The utilization of computers has been found to facilitate independent learning (Smith, 2008). Hani (2014) also claimed that computers help learners to study a language both inside and outside the classroom, providing authentic, individualized, and continuous learning activities. Pae (20 years old, male, majoring in Business Administration) from computer chat group stated as follows:

"I think computer chat encouraged me to study on my own. It is a powerful tool because computers give me control over my learning. By individualizing my needs, computers help promote learner independence, and at the same time, developed my learning strategies. While chatting with my chat partner, I use what I have learned or heard in class. In order to participate in chat, I frequently consult the online dictionary. This is beneficial for my language learning."

This is in line with the previous research (Lu, Hou, \& Huang, 2010), reporting that technologies shift from teacher-centered to learner-centered approach. Park (20 years old, female, majoring in Business Administration) from mobile chat group also stated that

"I believe these learner-centered learning environments increase learner autonomy and provide a broad range of language learning opportunities. Mobile chat is a new way of learning a language by giving chance to study by myself."

According to the previous research (Becker, 2000), computers encourage collaborative learning and more participation. Kang (21 years old, female, majoring in Mathematics) from computer chat group mentioned as follows:

"I have learned a lot from computer chat. With my chat partner, I can share my personal experiences and ideas in English. We give and receive feedback. During this interaction, we can check errors and mistakes. And accordingly, we have a chance for more accurate meaning rendering with better understanding." 
$\mathrm{Fu}$ (2013) suggested that the use of this communication technology can lead to more active participation. In particular, Jeong (21 years old, female, majoring in International Business) from mobile chat group pointed out that

"I can actively participate in mobile chat. Owing to their mobility and portability of mobile phones, there are no barriers of time and space in mobile chat. I can engage in chat anytime, anywhere. All I need is an Internet connection."

Hani (2014) asserted that technology helps learners to study a language both inside and outside the classroom, by reducing their apathy and a lack of the involvement in the learning process. Park (20 years old, female, majoring in Economics) from computer chat group stated as follows:

"I have enjoyed computer chat. Learning through chat was very interesting experience. Unlike in face-to-face communication, personal information is not a factor in limiting participation in chat activities. Since online chat interaction does not restrict participation, it feels like I can participate more equally in language learning activities. This improves confidence and decreases nervousness."

Kim (2017) also claimed that EFL learners enjoy synchronous chat. According to Choi (2004), online chat is highly valued by EFL learners with its easiness and practicality to use. A synchronous $\mathrm{CMC}$ like online chat provides a rich context for exploratory talk by motivating language learners (Pilkington \& Walker, 2003). Jeong (21 years old, female, majoring in International Business) from mobile chat group stated that

"Mobile phone is a basic necessity of my life. This is the most used communication tool for me today and I always bring my mobile phone. Through mobile chat for this class, I can keep studying English even when I don't feel like it. Almost every English learning class I've ever had was somewhat painful. I've been a naturally lazy girl with little patience. However, MALL is a motivating tool for me by providing access to a lot of communicative activities as well as reducing learning stress and anxiety. I think I can improve my English through mobile chat."

Overall, all interviewees reacted positively toward both computer chat and mobile chat. Previous researchers have also reported positive perceptions of online chat. Hudson and 
Bruckman (2002) insisted that online chat can help learners' positive attitudes towards language learning. Abrams (2003) also asserted that learners can improve their language proficiency through chat and this increased proficiency might be attributed to their positive reactions toward chat activities. When used in a foreign language learning, online chat can lead to target language development (Pennington, 1996).

However, interviewees revealed a criticism directed at CALL and MALL. Technical problems can always come up. Barr, Leakey, and Ranchoux (2005) warned that technology should not hinder learners' performance or progress. According to Dina and Ciornei (2013), computer technology is not always able to handle unexpected problems as teachers can. For example, Pae (20 years old, male, majoring in Business Administration) from computer chat group stated that

"For me, it was difficult to install and maintain KakaoTalk program through my computer. Sometimes, it discouraged me. Furthermore, I've never experienced in chat through computer. Training myself to use a computer took my time away from other learning activities. When problems arose, I was able to view the basic information via the help option. On the support pages, I could also get detailed. However, it took a lot of time for me to get used to it."

Financial problems are also related to costs of the acquisition of technology (Dina \& Ciornei, 2013). Some hardware and software programs can be very expensive. Schools may lack funds for CALL or MALL implementations. In that case, it can be problematic. In terms of mobile chat, Kim (23 years old, male, majoring in Physics)

"Not all learners can access MALL, I think. I had a problem with internet connection. Since there is still a lack of free wifi spots in Korea, I always had to worry about expensive communication fees when participating in online chat through mobile phone."

Overall, there were positive reactions toward online chat, demonstrating that synchronous CMC leads to independent and autonomous learning, encourages collaboration and participation, and increases positive, while reducing negative attitudes. Nevertheless, it seems important to investigate the barriers and challenges encountered in the usage of technology in language learning. As Kukulska-Hulme and Shield (2008) pointed out, limitations of technology use such as the problems of mobility and portability should also be considered. 


\section{CONCLUSION}

Most of chat programs are known to be useful not only for developing literacy skills such as reading and writing skills, but also for improving communicative skills including listening and speaking skills. However, not many studies have examined the use of synchronous CMC for both the speaking and writing development (Abrams, 2003; Chun, 1994; Warschauer, 1996). This sheds light on the necessity for an investigation on the effect of chat activities on speaking and writing skills. The study to be reported here aims to investigate whether using synchronous $\mathrm{CMC}$, namely chat, for foreign language learning improves the quality of speaking and writing skills. Particularly, given that there has been little research on the effectiveness of mobile chat, the current study investigated the effectiveness of chat tools by comparing computer chat and mobile chat.

Major findings of this study are as follows: As a result of engaging in computer chat, participants were able to improve their speaking fluency and speaking complexity. To be an outcome of experiencing mobile chat, participants could also develop their speaking fluency as well as writing fluency and writing complexity. When it comes to group differences, computer chat group performed better than mobile chat group for speaking fluency and speaking complexity. In terms of writing fluency and writing complexity, both computer chat and mobile chat turned out to be equally effective. Participants in both two groups revealed positive reactions toward online chat, indicating that chat can lead to independent and autonomous learning, encourage collaboration and participation, and increase positive attitudes such as motivation and confidence while reducing negative attitudes such as anxiety and stress.

This study discussed the differences between CALL and MALL related to online chat and revealed their positive effects on EFL learning. As Jeong (2010) argued, most previous CMC studies have investigated asynchronous CMC focusing on its effects on literacy skills, and little research has been conducted on the effectiveness of mobile chat. Given this, the current study finds new benefits and opens new possibilities for enhancing speaking and writing skills in EFL areas. Regarding pedagogical implications, findings of the present study provide insights into which type of chat tools can be more effectively integrated into EFL classroom. Based on the findings, computer chat should be employed to enhance speaking fluency and speaking complexity to maximize the pedagogical effects. For developing writing fluency and writing complexity, it seems desirable that either computer chat or mobile chat should be applied.

Language teachers should also consider that computers, mobile phones, or other technologies, can be instrumental in language instruction. Riasati, Allahyar, and Tan (2012) also argued that technology should be employed in language instruction to enhance learning and teaching. Technology is now calling for the establishment of relationship 
between the teacher and the computer. Excessive individualization of learning can result in denial of language teachers. It is risky to claim that technologies will delimit the teacher's role in a language classroom, but according to Hani (2014), they will definitely change the learning environment. However, "they are not in and of themselves instructors; rather, they are instructional tools" (Chinnery, 2006, p. 9). Accordingly, that technology may never replace language teachers. The effective use of technology in language learning needs the thoughtful application of language pedagogy. Teachers need to be concerned about excessive dependence on technology use (Kim, 2017).

Suggestions for future research can be also drawn based on the findings of the study. Since this study focused on speaking and writing, further studies on specific aspects or different skills of a language would contribute to the attempts at answering questions about the efficacy of mobile phone assisted language learning. It should be kept in mind that all aspects or skills of a language cannot be conveyed properly through mobile learning tools. Therefore, rather than making a general claim about the effectiveness of MALL, research should focus more on a specific aspect or skills of language for particular proficiency levels and certain learning contexts to ensure better understanding and use.

\section{REFERENCES}

Abrams, Z. I. (2003). The effect of synchronous and asynchronous CMC on oral performance in German. The Modern Language Journal, 87(2), 157-167.

AbuSeileek, A., \& AbuSa'aleek, A. (2012). Computer assisted language learning: Merits and demerits. Language in India, 12(4), 23-36.

Ahmadi, A., \& Sadeghi, E. (2016). Assessing English language learners' oral performance: A comparison of monologue, interview, and group oral test. Language Assessment Quarterly, 13(4), 341-358.

Al Abdel Halim, A. Q. (2009). Designing a computer-assisted language learning program and measuring its effect on Jordanian secondary school students' reading comprehension in English (Unpublished doctoral dissertation). Yarmouk University, Jordan.

Barr, D., Leakey, J., \& Ranchoux, A. (2005). Told like it is! An evaluation of an integrated oral development pilot project. Language Learning \& Technology, 9(3), 55-78.

Beatty, K. (2003). Teaching and researching computer-assisted language learning. Essex, England: Pearson Education.

Becker, H. (2000). Pedagogical motivations for student computer use that lead to student engagement. Educational Technology, 40(5), 5-17. 
Brown, E. (2001). Mobile learning explorations at the Stanford learning lab. Stanford, CA: Board of Trustees of the Leland Junior University.

Chinnery, G. M. (2006). Emerging technologies. Going to the mall: Mobile assisted language learning. Language Learning \& Technology, 10(1), 9-16.

Choi, H. (2004). EFL students' perceptions on synchronous English text chatting: Implications for its implementation. Multimedia Assisted Language Learning, 7(2), 35-63.

Chun, D. M. (1994). Using computer networking to facilitate the acquisition of interactive competence. System, 22(1), 17-31.

Colpaert, J. (2004). From courseware to coursewear? Computer Assisted Language Learning, 17(3-4), 261-266.

Dina, A. T., \& Ciornei, S. I. (2013). The advantages and disadvantages of computer assisted language learning and teaching for foreign languages. Procedia-Social and Behavioral Sciences, 76, 248-252.

Dörnyei, Z. (2007). Research methods in applied linguistics: Quantitative qualitative, and mixed methodologies. Oxford: Oxford University Press.

Ellis, R. (2009). The differential effects of three types of task planning on the fluency, complexity, and accuracy in L2 oral production. Applied Linguistics, 30(4), 474509.

Fallahkhair, S., Pemberton, L., \& Griffiths, R. (2007). Development of a cross-platform ubiquitous language learning service via mobile phone and interactive television. Journal of Computer Assisted Learning, 23(4), 312-325.

Foster, P., Tonkyn, A., \& Wigglesworth, G. (2000). Measuring spoken language: A unit for all reasons. Applied Linguistics, 21(3), 354-375.

$\mathrm{Fu}$, J. (2013). ICT in education: A critical literature review and its implications. International Journal of Education and Development Using Information and Communication Technology, 9(1), 112-125.

Han, J.-I., \& Kim, N.-Y. (2016). The effects of post-task CMC activities and task types on Korean EFL learners' oral performance. STEM Journal, 17(2), 109-135.

Han, W. (2008). Benefits and barriers of computer assisted language learning and teaching. US-China Foreign Language, 6(9), 40-43.

Hani, N. A. B. (2014). Benefits and barriers of computer assisted language learning and teaching in the Arab world: Jordan as a model. Theory and Practice in Language Studies, 4(8), 1609-1615.

Hudson, J. M., \& Bruckman, A. S. (2002). IRC Francais: The creation of an Internet-based SLA community. Computer Assisted Language Learning, 15(2), 109-134.

Hyland, K. (2002). Authority and invisibility: Authorial identity in academic writing. Journal of Pragmatics, 34(8), 1091-1112. 
ITU. (2009). The world in 2009: ICT facts and figures. Retrieved from https://www.itu.int/net/TELECOM/World/2009/newsroom/pdf/stats_ict200910.p df

Jeong, E. (2010). Comparison between the effects of SCMC and SCMC with peer feedback on EFL writing. Multimedia Assisted Language Learning, 13(2), 81-103.

Johnson, G. M. (2006). Synchronous and asynchronous text-based CMC in educational contexts: A review of recent research. TechTrends, 50(4), 46-53.

Kern, R. G. (1995). Restructuring classroom interaction with networked computers: Effects on quantity and characteristics of language production. The Modern Language Journal, 79(4), 457-476.

Kiernan, P. (2005). Storytelling with low-level learners: Developing narrative tasks. In C. Edwards \& J. Willis (Eds.), Teachers exploring tasks in English language teaching (pp. 58-68). Houndmills, UK: Palgrave Macmillan.

Kiernan, P., \& Aizawa, K. (2004). Cell phones in task based learning: Are cell phones useful language learning tools? ReCall, 16(1), 71-84.

Kim, N.-Y. (2017). Effects of different types of text-based chat on Korean EFL students' writing performance. Korean Journal of Linguistics, 42(3), 277-301.

Kim, S.-Y. (2002). Korean college students' reflections of English language learning via CMC and FFC. Multimedia Assisted Language Learning, 5(2), 9-28.

Kukulska-Hulme, A., \& Shield, L. (2008). An overview of mobile assisted language learning: From content delivery to supported collaboration and interaction ReCALL, 20(3), 271-289.

Larsen-Freeman, D. (2006). The emergence of complexity, fluency, and accuracy in the oral and written production of five Chinese learners of English. Applied Linguistics, 27(4), 590-619.

$\mathrm{Lu}$, M. (2008). Effectiveness of vocabulary learning via mobile phone. Journal of Computer Assisted Learning, 24(6), 515-525.

Lu, Z., Hou, L., \& Huang, X. (2010). A research on a student-centered teaching model in an ICT based English audio-video speaking class. International Journal of Education and Development Using Information and Communication Technology, 6(3), 101-123.

Nah, K. C., White, P., \& Sussex, R. (2008). The potential of using a mobile phone to access the Internet for learning EFL listening skills within a Korean context. ReCALL, 20(3), 331-347.

Pennington, M. (1996). Writing the natural way on computer. Computer Assisted Language Learning, 9(2-3), 125-142.

Pettit, J., \& Kukulska-Hulme, A. (2007). Going with the grain: Mobile devices in practice. Australasian Journal of Educational Technology, 23(1), 17-33. 
Pilkington, R., \& Walker, S. A. (2003). Facilitating debate in networked learning: Reflecting on online synchronous discussion in higher education. Instructional Science, 31(1-2), 41-63.

Riasati, M., Allahyar, N., \& Tan, K. (2012). Technology in language education: Benefits and barriers. Journal of Education and Practice, 3(5), 25-30.

Salaberry, M. R. (2001). The use of technology for second language learning and teaching: A retrospective. The Modern Language Journal, 85(1), 39-56.

Saran, M., Seferoglu, G., \& Cagiltay, K. (2009). Mobile assisted language learning: English pronunciation at learners' fingertips. Egitim Arastirmalari-Eurasian Journal of Educational Research, 34, 97-114.

Skehan, P. (2001). Tasks and language performance assessment. In M. Bygate, P. Skehan, \& M. Swain (Eds.), Researching pedagogic tasks: Second language learning, teaching, and testing (pp. 23-48). Harlow, UK: Pearson Education.

Smith, B. (2008). Methodological hurdles in capturing CMC data: The case of the missing self-repair. Language Learning \& Technology, 12(1), 85-103.

Sullivan, N., \& Pratt, E. (1996). A comparative study of two ESL writing environments: A computer-assisted classroom and a traditional oral classroom. System, 24(4), 491501.

Thornton, P., \& Houser, C. (2005). Using mobile phones in English education in Japan. Journal of Computer Assisted Learning, 21(3), 217-228.

Volle, L. M. (2005). Analyzing oral skills in voice e-mail and online interviews. Language Learning \& Technology, 9(3), 146-163.

Warschauer, M. (1996). Comparing face-to-face and electronic discussion in the second language classroom. CALICO Journal, 13(2), 7-26.

Wolf-Quintero, K., Inagaki, S., \& Kim, H. (1998). Second language development in writing: Measures of fluency accuracy and complexity. Honolulu, HI: University of Hawaii at Manoa.

Yamaguchi, T. (2005, August). Vocabulary learning with a mobile phone. Paper presented at the 10th Anniversary Conference of Pan-Pacific Association of Applied Linguistics, Edinburgh, UK.

Yoon, S.-K., \& Han, J.-I. (2004). A case study on the effects of the use of chatterbot and messenger on the productive skills of Korean EFL learners. Multimedia Assisted Language Learning, 7(2), 269-292.

Yuan, F., \& Ellis, R. (2003). The effects of pre-task planning and on-line planning on fluency, complexity and accuracy in L2 monologic oral production. Applied Linguistics, 24(1), 1-27. 
Applicable level: college

Keywords: computer chat, mobile chat, EFL speaking and writing, fluency, accuracy, complexity

Kim, Na-Young

Department of General Education

Sehan University

33, Sehandae-gil, Sinpyeong-myeon, Dangjin-si, Chungcheongnam-do, Korea

E-mail: nykim@sehan.ac.kr

Received: January 21, 2018

Revised version: May 13, 2018

Accepted: May 26, 2018 